\title{
Review
}

Journal of Innate

Immunity
J Innate Immun 2011;3:258-263

DOI: $\underline{10.1159 / 000323923}$
Received: October 21, 2010

Accepted after revision: December 7, 2010

Published online: March 11, 2011

\section{The Bidirectional Crosstalk between Human Dendritic Cells and Natural Killer Cells}

\author{
Rebekka Wehner Kristin Dietze Michael Bachmann Marc Schmitz \\ Institute of Immunology, Medical Faculty, Technical University of Dresden, Dresden, Germany
}

\section{Key Words}

Dendritic cells $\cdot$ Natural killer cells $\cdot$ Innate immunity

\begin{abstract}
Dendritic cells (DCs) are professional antigen-presenting cells, which display an extraordinary capacity to induce T-cell responses. Recent findings revealed that DCs also play a crucial role in the activation of natural killer (NK) cells representing important effectors in the innate immune defense against viruses and tumors. Here, we summarize various studies investigating the bidirectional crosstalk between human DCs and NK cells. In this context, it has been reported that DCs efficiently enhance CD69 expression, proliferation, interferon (IFN)- $\gamma$ secretion and cytotoxic activity of NK cells. Cell membrane-associated molecules as well as soluble factors such as interleukin-12, tumor necrosis factor- $\alpha$ and type I IFNs contributed to DC-mediated NK cell activation. Reciprocally, the ability of human NK cells to enhance the immunostimulatory capacity of DCs was shown. Thus, NK cells promoted the maturation of DCs and markedly augmented their capacity to produce proinflammatory cytokines and to stimulate T-cell responses. The NK cell-mediated effects on DCs were dependent on cell membrane-associated molecules such as NKp30 and soluble factors such as tumor ne-
\end{abstract}

crosis factor- $\alpha$ and IFN- $\gamma$. In conclusion, the reciprocal activating interaction between human DCs and NK cells may play a pivotal role in the immune defense against viruses and tumors.

Copyright $\odot 2011$ S. Karger AG, Basel

\section{Introduction}

Dendritic cells (DCs) are professional antigen-presenting cells, which display an extraordinary capacity to induce and stimulate $\mathrm{CD} 8^{+}$cytotoxic $\mathrm{T}$ lymphocytes (CTLs) and $\mathrm{CD}^{+}{ }^{+} \mathrm{T}$ cells [1]. CD8 ${ }^{+}$CTLs efficiently recognize and destroy virus-infected and tumor cells, which expose antigen-derived peptides in complex with human leukocyte antigen (HLA) class I molecules. $\mathrm{CD} 4^{+} \mathrm{T}$ cells recognizing peptides in the context of HLA class II molecules also play an important role in adaptive immunity. $\mathrm{CD} 4^{+} \mathrm{T}$ cells improve the capacity of DCs to induce CTLs and directly support the expansion of CTLs by secreting cytokines such as interleukin (IL)-2. Owing to their unique T-cell-stimulatory capacity, DCs evolved as promising candidates for vaccination protocols in tumor therapy. Animal models demonstrated that tumor-associated antigen-presenting DCs are capable of inducing protec-

\section{KARGER}

Fax +4161306 1234

E-Mail karger@karger.ch

www.karger.com (c) 2011 S. Karger AG, Basel

1662-811X/11/0033-0258\$38.00/0

Accessible online at:

www.karger.com/jin
Dr. Marc Schmitz

Institute of Immunology, Medical Faculty

Technical University of Dresden, Fetscherstr. 74

DE-01307 Dresden (Germany)

Tel. +49351 458 6501, E-Mail marc.schmitz@tu-dresden.de 
tive and therapeutic antitumor responses [2]. In addition, clinical trials enrolling tumor patients revealed promising immunologic and clinical responses of tumor-associated antigen-loaded DCs administered as a vaccine [3].

Recent findings indicated that DCs also play an important role in the activation of natural killer (NK) cells, which represent important effectors in innate immunity [4]. Human blood NK cells can be subdivided into two distinct subsets based on the cell surface density of CD56 expression [5]. CD56 ${ }^{\mathrm{dim}} \mathrm{CD} 16^{+} \mathrm{NK}$ cells represent the majority (approximately 90\%) of NK cells and have a high cytotoxic capacity. CD56 ${ }^{\text {bright }} \mathrm{CD} 16^{-} \mathrm{NK}$ cells comprise approximately $10 \%$ of NK cells and produce high levels of cytokines such as interferon (IFN) $-\gamma$ and tumor necrosis factor (TNF)- $\alpha$, which play an important role in modulating immune responses. Due to their functional properties, NK cells essentially contribute to the elimination of tumor and virus-infected cells. When investigating the potential of mouse DCs to stimulate NK cells, it has been reported that FMS-like tyrosine kinase 3 ligand-expanded or adoptively transferred DCs markedly enhance NK cell-dependent antitumor effects in mice with major histocompatibility complex class-I-negative tumors [6]. Following such findings, the bidirectional crosstalk between human DCs and NK cells has been explored. The results are summarized in this review article.

\section{Human DCs Improve Effector Functions of NK Cells}

In recent years, several studies investigated the potential of human DCs to influence phenotype and function of NK cells. Most of these analyses were performed with monocyte-derived DCs. To obtain immature DCs, monocytes were maintained for several days in the presence of granulocyte macrophage colony-stimulating factor and IL-4. For maturation and stimulation, immature DCs were cultivated in the presence of additional factors such as TNF- $\alpha$, IL-1 $\beta$, IFN- $\alpha$, lipopolysaccharide (LPS) and polyinosinic-polycytidylic acid. It has been demonstrated that monocyte-derived DCs markedly enhance the expression of the activation marker CD69 on the surface of NK cells [7-12]. Soluble factors such as type I IFNs as well as direct cell-to-cell contact were shown to be important for DC-mediated upregulation of CD69 on NK cells [7-9, 12]. Thus, major histocompatibility complex class-I-related chain (MIC) A and B representing ligands for the activating NK cell receptor NKG2D were induced on monocyte-derived DCs upon IFN- $\alpha$ stimulation and contributed to the upregulation of CD69 on NK cells [9]. More recently, it has been reported that the recognition of influenza-infected monocyte-derived DCs by the activating NK cell receptors NKG2D and NKp46 results in an increased CD69 expression on NK cells [12].

Further studies revealed that human monocyte-derived DCs are also able to efficiently promote NK cell proliferation [10, 13-17]. When distinguishing between CD56 ${ }^{\text {dim }} \mathrm{CD}_{16}{ }^{+}$and $\mathrm{CD} 56^{\text {bright }} \mathrm{CD} 16^{-} \mathrm{NK}$ cell subsets, Vitale et al. [10] demonstrated that activated monocytederived DCs only increased expansion of CD56 bright $\mathrm{CD} 16^{-} \mathrm{NK}$ cells. In contrast, IL-2 induced a non-selected, homogeneous proliferation of both NK cell populations. Cell-to-cell contact essentially contributed to DC-mediated NK cell proliferation. Thus, it has been documented that the interaction between CD40 on DCs and CD40L on NK cells as well as B7 molecules on DCs and CD28 on NK cells plays an important role [13]. IL-15 expressed on the surface of activated monocyte-derived DCs also mediated enhanced NK cell proliferation [15]. In addition, IL-12 contributed to this effect [13].

Further studies explored the potential of monocytederived DCs to modulate cytokine production of NK cells. Monocyte-derived DCs induced the release of IFN$\gamma$ by NK cells $[9,10,12-15,17-19]$. When investigating the underlying mechanisms, it has been demonstrated that IL-12 essentially contributes to this effect $[9,10,12$, $13,15,18]$. DC-mediated induction of IFN- $\gamma$ production by NK cells also required direct cell-to-cell contact [12]. Recently, Borg et al. [18] reported that the formation of stimulatory synapses promoted the polarized secretion of preassembled stores of IL-12 by DCs towards NK cells. In this context, the interaction of CX3CL1 expressed by DCs and CX3CR1 on NK cells induced DC-mediated IFN- $\gamma$ production by NK cells [19]. However, whereas IL-12 plays a major role for the induction of NK cell IFN- $\gamma$ secretion by LPS-activated DCs, other factors appear to be important for IFN- $\alpha$-stimulated DCs mediating the same effect. Thus, it has been shown that the expression of the NKG2D ligands MICA and MICB on IFN- $\alpha$-treated DCs is responsible for the induction of IFN- $\gamma$ production by NK cells [9]. In addition, Draghi et al. [12] reported that NK cell IFN- $\gamma$ secretion mediated by influenza virus-infected DCs is dependent on the ligation of the activating NK cell receptors NKp46 and NKG2D.

The cytotoxic potential of NK cells plays an important role in the elimination of virus-infected and tumor cells. Therefore, the impact of human monocyte-derived DCs on the cytotoxic activity of NK cells was investigated. It has been documented that DCs efficiently improve this functional property of NK cells $[8,9,12,13,16,17,19,20]$. 
The DC-mediated enhancement of NK cell cytolytic activity was mediated by soluble factors and direct cell-tocell contact $[8,13,20]$. Thus, IL-12 secreted by activated DCs as well as CX3CL1, MICA and MICB expressed on the surface of DCs contributed to the improved cytolytic potential of NK cells $[9,13,19]$. Besides efficient tumor cell killing, activated NK cells were also able to lyse monocyte-derived DCs [12, 14, 21-23]. Mature DCs were less sensitive to NK cell-mediated lysis, which was most probably due to a higher expression level of HLA class I molecules that bind to inhibitory NK cell receptors [21]. Recognition of monocyte-derived DCs was mainly mediated through NKp30 and to a lesser extent by NKp46 and NKG2D [14]. Further studies demonstrated that additional activating NK cell receptors such as CD94/ NKD2A and DNAX accessory molecule 1 are involved in NK cell-mediated lysis of DCs $[21,23]$.

In addition to monocyte-derived DCs, the potential of human DCs derived from $\mathrm{CD} 34^{+}$cord blood cells to modulate the effector functions of NK cells was investigated [24]. For this, DCs were generated from $\mathrm{CD} 34^{+}$cord blood cells after several days in the presence of various cytokines. Yu et al. [24] demonstrated the capability of $\mathrm{CD} 34^{+}$cell-derived DCs to significantly improve the tumor-directed cytotoxicity and IFN- $\gamma$ secretion of NK cells. Cell-to-cell contact as well as IL-12 and IL-18 secreted by DCs contributed to these effects.

Whereas most current findings are based on monocyte-derived DCs, which are generated after several days in the presence of various cytokines, studies investigating the interaction between native human DCs and NK cells are limited. Several studies provided evidence that native human myeloid and plasmacytoid blood DCs $[25,26]$ efficiently promote NK cell activation. Thus, it has been demonstrated that polyinosinic-polycytidylic acid-stimulated $\mathrm{CD} 1 \mathrm{c}^{+}$myeloid DCs and $\mathrm{CD} 1 \mathrm{c}^{+} / \mathrm{BDCA}^{-} 3^{+}$myeloid DCs strongly increased CD69 expression, IFN- $\gamma$ secretion and tumor-directed cytotoxicity of NK cells $[27,28]$. Whereas type I IFNs and IL-12 were critical for improved cytolytic activity of NK cells, increased CD69 expression was dependent on type I IFNs and TNF- $\alpha$. Furthermore, IL-12 and cell-to-cell contact essentially contributed to $\mathrm{CD} \mathrm{c}^{+} \mathrm{DC}$-mediated enhancement of IFN- $\gamma$ secretion by NK cells $[27,28]$. Recently, we documented the ability of LPS-stimulated 6-sulfo LacNAc ${ }^{+}$(slan) DCs, which represent another myeloid blood DC subset $[29,30]$, to efficiently activate resting NK cells [31]. LPS-stimulated slanDCs augmented the surface expression of CD69 and markedly improved IFN- $\gamma$ release as well as tumor-directed cytotoxicity of NK cells [31]. When evaluating the underlying mechanisms for NK cell activation by slanDCs in response to LPS, we found that IL-12 plays a crucial role in this process. However, in contrast to slanDCs activated by LPS, IFN- $\gamma$-stimulated slanDCs improve NK cell activation through cell-to-cell contact [32]. When investigating native plasmacytoid DCs [26], it has been reported that inactivated influenza virus- or CpG oligodeoxynucleotide-stimulated plasmacytoid DCs promote CD69 expression, proliferation, IFN- $\gamma$ secretion and tumoricidal potential of NK cells $[27,33,34]$. Type I IFNs and TNF- $\alpha$ released by plasmacytoid DCs were critical for enhanced CD69 expression on NK cells [27, 33]. Cellto-cell contact as well as soluble molecules such as type I IFNs and glucocorticoid-induced TNF receptor ligand contributed to the ability of plasmacytoid DCs to augment IFN- $\gamma$ secretion and cytotoxic activity of NK cells $[27,33,34]$.

\section{NK Cells Efficiently Promote the Immunostimulatory Properties of Human DCs}

Recent data illustrated the potential of NK cells to enhance the immunostimulatory capacity of DCs. In this context, it has been shown that NK cells efficiently promote the differentiation and maturation of monocytederived DCs [7, 22, 35-39]. This NK cell-mediated effect on DCs was dependent on the engagement of the cell membrane-associated activating NK cell receptor NKp30 and soluble factors such as TNF- $\alpha$, IFN- $\gamma$ and high-mobility group box protein $1[7,8,22,35,36,39]$.

Further studies demonstrated that NK cells significantly augment the production of immunostimulatory cytokines by human monocyte-derived DCs. Thus, it has been reported that NK cells markedly increase TNF- $\alpha$ release by DCs, which is based on cell-to-cell contact [7, 38]. Furthermore, the capacity of DCs to produce IL-12 was profoundly enhanced by NK cells [7, 8, 35]. Cell-tocell contact as well as IFN- $\gamma$ and TNF- $\alpha$ contributed to this effect $[7,35]$.

Following the findings that NK cells promote maturation and cytokine production of monocyte-derived DCs, the impact of NK cells on DC-mediated T-cell proliferation and differentiation was explored. Several studies showed that NK cells markedly improve the capability of monocyte-derived DCs to stimulate T-cell proliferation, to differentiate naïve $\mathrm{CD} 4^{+} \mathrm{T}$ lymphocytes into IFN- $\gamma$ producing Th1 cells and to promote IFN- $\gamma$ production by $\mathrm{CD}^{+}$CTLs $[8,35,38]$. 


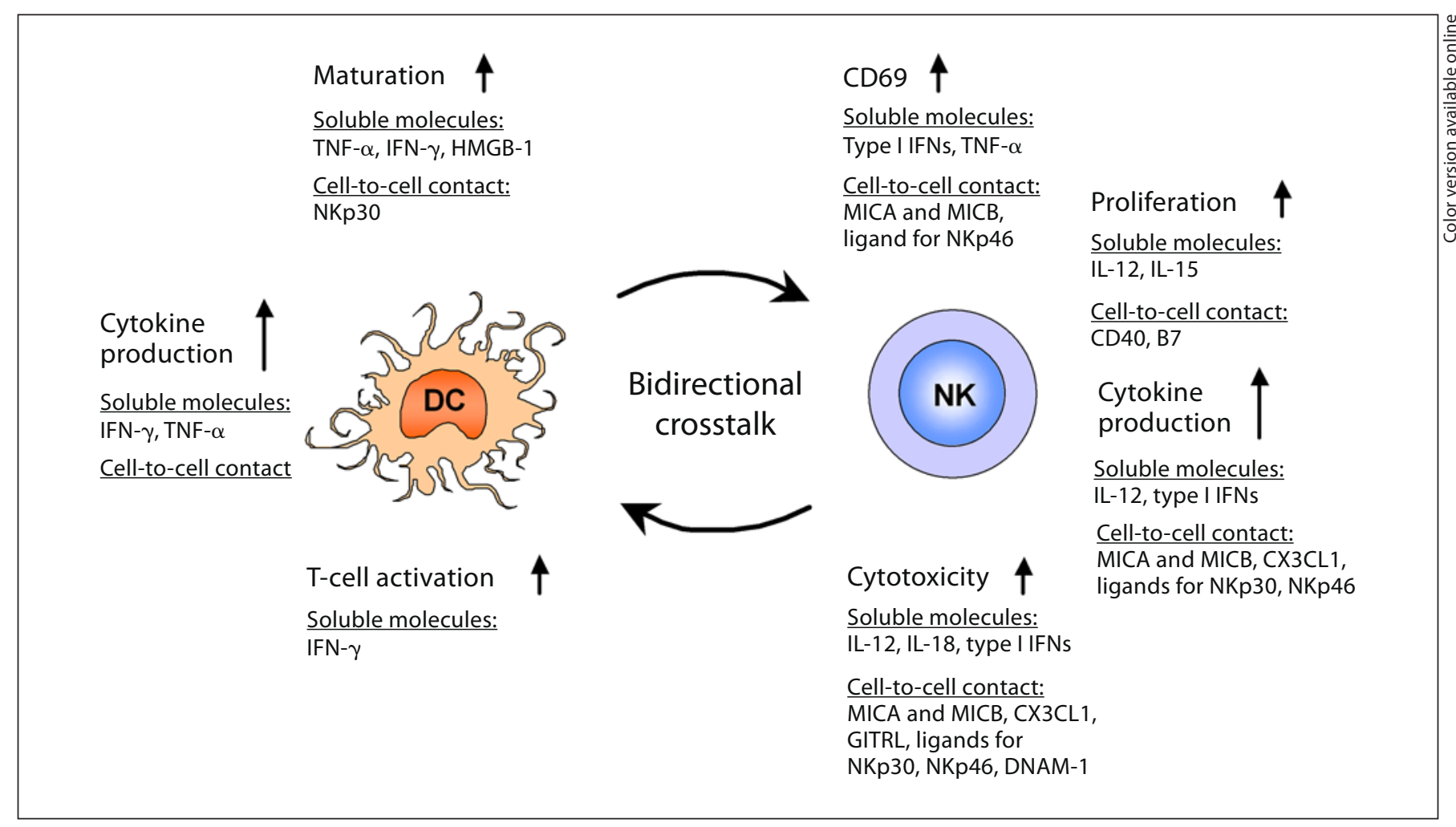

Fig. 1. Bidirectional crosstalk between human DCs and NK cells. DCs efficiently enhance CD69 expression, proliferation, IFN- $\gamma$ production and cytotoxic activity of NK cells. Cell membraneassociated molecules like MICA and MICB as well as soluble factors like IL-12 and type I IFNs contributed to DC-mediated NK cell activation. Reciprocally, NK cells promote DC maturation and improve their capability to secrete proinflammatory cyto-

When evaluating the impact of NK cells on native human DCs, Gerosa et al. [27] documented that NK cells promote the maturation of $\mathrm{CD} 1 \mathrm{c}^{+}$myeloid DCs, which is dependent on cell-to-cell contact. However, the secretion of IL-12 by CD1c ${ }^{+}$myeloid DCs was not induced by NK cells. Furthermore, we demonstrated that NK cells efficiently promote the maturation of myeloid slanDCs in the absence of exogenous cytokines [31]. NK cells also profoundly enhanced the secretion of IL-12 and reduced the production of the immunosuppressive cytokine IL-10 by slanDCs. IFN- $\gamma$ released by NK cells as well as cell-tocell contact contributed to these effects. Further data revealed that the crosstalk between slanDCs and NK cells improved the capacity of LPS-stimulated slanDCs to favor the differentiation of naïve $\mathrm{CD} 4^{+} \mathrm{T}$ cells into IFN- $\gamma$ producing Th1 cells [31]. Studies investigating the impact of NK cells on phenotype and function of plasmacytoid DCs illustrated that NK cells promote DC maturation kines and to stimulate T-cell responses. The NK cell-mediated effects on DCs are dependent on cell membrane-associated molecules such as NKp30 and soluble factors such as IFN- $\gamma$ and TNF$\alpha$. HMGB-1 = High-mobility group box protein 1; GITRL = glucocorticoid-induced TNF receptor-ligand; DNAM-1 = DNAX accessory molecule 1.

and strongly enhance IFN- $\alpha$ and TNF- $\alpha$ production by this DC subset in the presence of suboptimal CpG oligodeoxynucleotide concentrations [27]. Cell-to-cell contact was essential for these effects. Furthermore, it has been reported that NK cells promote IFN- $\alpha$ and IL- 6 release by plasmacytoid DCs [40].

\section{Conclusion}

DCs are professional antigen-presenting cells, which display an extraordinary capacity to induce and maintain T-cell responses. Recent findings revealed that DCs also play a crucial role in the activation of NK cells representing important effectors in the innate immune defense against viruses and tumors. In this context, it has been demonstrated that human monocyte-derived DCs as well as native human DCs in response to different stimuli ef- 
ficiently improve CD69 expression, proliferation, IFN- $\gamma$ secretion and cytotoxic activity of NK cells (fig. 1). These DC-mediated effects are critically dependent on cell membrane-associated molecules as well as on soluble molecules (fig. 1). Interestingly, the contribution of the various molecules is critically dependent on the DC subset as well as on the stimulus used for DC activation. Reciprocally, it has been shown that NK cells promote maturation and enhance the secretion of proinflammatory cytokines by monocyte-derived DCs and native human DCs (fig. 1). Cell membrane-associated molecules as well as soluble molecules contributed to these NK cell-mediated effects (fig. 1). Furthermore, NK cells markedly enhanced the capacity of DCs to stimulate and differentiate
T cells. All these findings demonstrate a reciprocal activating crosstalk between human DCs and NK cells, which may play a pivotal role in the regulation of the immune defense against viruses and tumors. They may also pave the way for the design of novel immunotherapeutic strategies for the treatment of infectious diseases and tumors.

\section{Acknowledgement}

Our studies reported in this paper were supported by grants from the Medical Faculty, Technical University of Dresden.

\section{References}

1 Steinman RM, Banchereau J: Taking dendritic cells into medicine. Nature 2007;449: 419-426.

-2 Mayordomo JI, Zorina T, Storkus WJ, Zitvogel L, Celluzzi C, Falo LD, Melief CJ, Ildstad ST, Kast WM, Deleo AB: Bone marrow-derived dendritic cells pulsed with synthetic tumour peptides elicit protective and therapeutic antitumour immunity. Nat Med 1995 1:1297-1302

-3 Nestle FO, Alijagic S, Gilliet M, Sun Y, Grabbe S, Dummer R, Burg G, Schadendorf D: Vaccination of melanoma patients with peptide- or tumor lysate-pulsed dendritic cells. Nat Med 1998;4:328-332.

4 Moretta A: The dialogue between human natural killer cells and dendritic cells. Curr Opin Immunol 2005; 17:306-311.

-5 Farag SS, Caligiuri MA: Human natural killer cell development and biology. Blood Rev 2006;20:123-137.

6 Fernandez NC, Lozier A, Flament C, Ricciardi-Castagnoli P, Bellet D, Suter M, Perricaudet M, Tursz T, Maraskovsky E, Zitvogel L: Dendritic cells directly trigger NK cell functions: cross-talk relevant in innate antitumor immune responses in vivo. Nat Med 1999;5:405-411.

-7 Piccioli D, Sbrana S, Melandri E, Valiante NM: Contact-dependent stimulation and inhibition of dendritic cells by natural killer cells. J Exp Med 2002;195:335-341.

-8 Gerosa F, Baldani-Guerra B, Nisii C, Marchesini V, Carra G, Trinchieri G: Reciprocal activating interaction between natural killer cells and dendritic cells. J Exp Med 2002;195: 327-333.
9 Jinushi M, Takehara T, Kanto T, Tatsumi T, Groh V, Spies T, Miyagi T, Suzuki T, Sasaki Y, Hayashi N: Critical role of MHC class Irelated chain A and B expression on IFN-alpha-stimulated dendritic cells in NK cell activation: impairment in chronic hepatitis $\mathrm{C}$ virus infection. J Immunol 2003;170:12491256.

10 Vitale M, Della Chiesa M, Carlomagno S, Romagnani C, Thiel A, Moretta L, Moretta A: The small subset of CD56 $6^{\text {bright }}$. Eur J Immunol 2004;34:1715-1722.

- 11 Brilot F, Strowig T, Roberts SM, Arrey F, Munz C: NK cell survival mediated through the regulatory synapse with human DCs requires IL-15Ralpha. J Clin Invest 2007;117: 3316-3329.

12 Draghi M, Pashine A, Sanjanwala B, Gendzekhadze K, Cantoni C, Cosman D, Moretta A, Valiante NM, Parham P: NKp46 and NKG2D recognition of infected dendritic cells is necessary for NK cell activation in the human response to influenza infection. J Immunol 2007; 178:2688-2698.

13 Amakata Y, Fujiyama Y, Andoh A, Hodohara K, Bamba T: Mechanism of NK cell activation induced by coculture with dendritic cells derived from peripheral blood monocytes. Clin Exp Immunol 2001;124:214-222.

14 Ferlazzo G, Tsang ML, Moretta L, Melioli G, Steinman RM, Munz C: Human dendritic cells activate resting natural killer (NK) cells and are recognized via the NKp30 receptor by activated NK cells. J Exp Med 2002;195: 343-351.

15 Ferlazzo G, Pack M, Thomas D, Paludan C, Schmid D, Strowig T, Bougras G, Muller WA, Moretta L, Munz C: Distinct roles of IL-12 and IL-15 in human natural killer cell activation by dendritic cells from secondary lymphoid organs. Proc Natl Acad Sci USA 2004; 101:16606-16611.
16 Munz C, Dao T, Ferlazzo G, de Cos MA, Goodman K, Young JW: Mature myeloid dendritic cell subsets have distinct roles for activation and viability of circulating human natural killer cells. Blood 2005;105:266-273.

17 Vujanovic L, Szymkowski DE, Alber S, Watkins SC, Vujanovic NL, Butterfield LH: Virally infected and matured human dendritic cells activate natural killer cells via cooperative activity of plasma membrane-bound TNF and IL-15. Blood 2010;116:575-583.

$\checkmark 18$ Borg C, Jalil A, Laderach D, Maruyama K, Wakasugi H, Charrier S, Ryffel B, Cambi A, Figdor C, Vainchenker W, Galy A, Caignard A, Zitvogel L: NK cell activation by dendritic cells (DCs) requires the formation of a synapse leading to IL-12 polarization in DCs. Blood 2004;104:3267-3275.

19 Pallandre JR, Krzewski K, Bedel R, Ryffel B, Caignard A, Rohrlich PS, Pivot X, Tiberghien P, Zitvogel L, Strominger JL, Borg C: Dendritic cell and natural killer cell cross-talk: a pivotal role of CX3CL1 in NK cytoskeleton organization and activation. Blood 2008;112: 4420-4424.

-20 Nishioka Y, Nishimura N, Suzuki Y, Sone S: Human monocyte-derived and CD83(+) blood dendritic cells enhance NK cell-mediated cytotoxicity. Eur J Immunol 2001;31: 2633-2641.

21 Della Chiesa M, Vitale M, Carlomagno S, Ferlazzo G, Moretta L, Moretta A: The natural killer cell-mediated killing of autologous dendritic cells is confined to a cell subset expressing CD94/NKG2A, but lacking inhibitory killer Ig-like receptors. Eur J Immunol 2003;33:1657-1666.

22 Semino C, Angelini G, Poggi A, Rubartelli A: $\mathrm{NK} / \mathrm{iDC}$ interaction results in IL-18 secretion by DCs at the synaptic cleft followed by NK cell activation and release of the DC maturation factor HMGB1. Blood 2005;106:609-616. 
23 Pende D, Castriconi R, Romagnani P, Spaggiari GM, Marcenaro S, Dondero A, Lazzeri E, Lasagni L, Martini S, Rivera P, Capobianco A, Moretta L, Moretta A, Bottino C: Expression of the DNAM-1 ligands, nectin-2 (CD112) and poliovirus receptor (CD155), on dendritic cells: relevance for natural killerdendritic cell interaction. Blood 2006;107: 2030-2036.

24 Yu Y, Hagihara M, Ando K, Gansuvd B, Matsuzawa $\mathrm{H}$, Tsuchiya T, Ueda Y, Inoue $\mathrm{H}$, Hotta T, Kato S: Enhancement of human cord blood CD34+ cell-derived NK cell cytotoxicity by dendritic cells. J Immunol 2001;166: 1590-1600.

-25 Piccioli D, Tavarini S, Borgogni E, Steri V, Nuti S, Sammicheli C, Bardelli M, Montagna D, Locatelli F, Wack A: Functional specialization of human circulating CD16 and CD1c myeloid dendritic-cell subsets. Blood 2007; 109:5371-5379.

26 Lande R, Gilliet M: Plasmacytoid dendritic cells: key players in the initiation and regulation of immune responses. Ann NY Acad Sci 2010;1183:89-103.

-27 Gerosa F, Gobbi A, Zorzi P, Burg S, Briere F, Carra G, Trinchieri G: The reciprocal interaction of NK cells with plasmacytoid or myeloid dendritic cells profoundly affects innate resistance functions. J Immunol 2005; 174:727-734.

28 Perrot I, Deauvieau F, Massacrier C, Hughes N, Garrone P, Durand I, Demaria O, Viaud N, Gauthier L, Blery M, Bonnefoy-Berard N, Morel Y, Tschopp J, Alexopoulou L, Trinchieri G, Paturel C, Caux C: TLR3 and Rig-like receptor on myeloid dendritic cells and Riglike receptor on human NK cells are both mandatory for production of IFN-gamma in response to double-stranded RNA. J Immunol 2010;185:2080-2088.
29 Schakel K, Kannagi R, Kniep B, Goto Y, Mitsuoka C, Zwirner J, Soruri A, von Kietzell M, Rieber E: 6-Sulfo LacNAc, a novel carbohydrate modification of PSGL-1, defines an inflammatory type of human dendritic cells. Immunity 2002; 17:289-301.

30 Schakel K, von Kietzell M, Hansel A, Ebling A, Schulze L, Haase M, Semmler C, Sarfati M, Barclay AN, Randolph GJ, Meurer M, Rieber EP: Human 6-sulfo LacNAc-expressing dendritic cells are principal producers of early interleukin-12 and are controlled by erythrocytes. Immunity 2006;24: 767-777.

31 Wehner R, Lobel B, Bornhauser M, Schakel K, Cartellieri M, Bachmann M, Rieber EP, Schmitz M: Reciprocal activating interaction between 6-sulfo LacNAc+ dendritic cells and NK cells. Int J Cancer 2009;124: 358-366.

32 Schmitz M, Zhao S, Deuse Y, Schakel K, Wehner R, Wohner H, Holig K, Wienforth F, Kiessling A, Bornhauser M, Temme A, Rieger MA, Weigle B, Bachmann M, Rieber EP: Tumoricidal potential of native blood dendritic cells: direct tumor cell killing and activation of NK cell-mediated cytotoxicity. J Immunol 2005; 174:4127-4134.

33 Romagnani C, Della Chiesa M, Kohler S, Moewes B, Radbruch A, Moretta L, Moretta A, Thiel A: Activation of human NK cells by plasmacytoid dendritic cells and its modulation by CD4+ T helper cells and CD4+CD$25^{\text {hi }}$ T regulatory cells. Eur J Immunol 2005; 35:2452-2458.

-34 Hanabuchi S, Watanabe N, Wang YH, Wang YH, Ito T, Shaw J, Cao W, Qin FX, Liu YJ: Human plasmacytoid predendritic cells activate NK cells through glucocorticoid-induced tumor necrosis factor receptor-ligand (GITRL). Blood 2006;107:3617-3623.
5 Mailliard RB, Son YI, Redlinger R, Coates PT, Giermasz A, Morel PA, Storkus WJ, Kalinski P: Dendritic cells mediate NK cell help for Th1 and CTL responses: two-signal requirement for the induction of NK cell helper function. J Immunol 2003;171:2366-2373.

36 Vitale M, Della Chiesa M, Carlomagno S, Pende D, Arico M, Moretta L, Moretta A: NK-dependent DC maturation is mediated by TNFalpha and IFNgamma released upon engagement of the NKp30 triggering receptor. Blood 2005; 106:566-571.

37 Zhang AL, Colmenero P, Purath U, Teixeira de MC, Hueber W, Klareskog L, Tarner IH, Engleman EG, Soderstrom K: Natural killer cells trigger differentiation of monocytes into dendritic cells. Blood 2007;110:24842493.

-38 Agaugue S, Marcenaro E, Ferranti B, Moretta L, Moretta A: Human natural killer cells exposed to IL-2, IL-12, IL-18, or IL-4 differently modulate priming of naive $\mathrm{T}$ cells by monocyte-derived dendritic cells. Blood 2008;112:1776-1783.

39 Morandi B, Mortara L, Carrega P, Cantoni C, Costa G, Accolla RS, Mingari MC, Ferrini S, Moretta L, Ferlazzo G: NK cells provide helper signal for CD8+ T cells by inducing the expression of membrane-bound IL-15 on DCs. Int Immunol 2009;21:599-606.

40 Della Chiesa M, Romagnani C, Thiel A, Moretta L, Moretta A: Multidirectional interactions are bridging human NK cells with plasmacytoid and monocyte-derived dendritic cells during innate immune responses. Blood 2006;108:3851-3858. 